\title{
PENGARUH KEKUATAN BENDING DAN TARIK \\ BAHAN KOMPOSIT BER PENGUAT SEKAM PADI \\ DENGAN MATRIK UREA FORMALDEHIDE
}

\author{
Harini \\ Program Studi Teknik Mesin Universitas 17 agustus 1945 Jakarta \\ yos.nofendri@uta45jakarta.ac.id
}

\begin{abstract}
ABSTRAK
Tujuan penelitian adalah untuk mengetahui kekuatan bending dan impact yang optimal dari komposit berpenguat sekam padi bermatrik urea formaldehyde pada fraksi volume 40\%, 50\%, 60\%, 70\% dengan variasi ketebalan-ketebalan 5mm, 10mm, 15mm, 20mm, dengan perlakuan alkali serta mengetahui jenis patahan dengan pengamatan makro pada specimen yang memiliki harga optimal dari pengujian bending dan impact.

Pembuatan dengan cara press mold, pengujian bending yang dilakukan dengan acuan standar ASTM D 790-02 dan impak charpy dengan acuan standart ASTM D 256-00.

Hasil pengujian didapat pengaruh alkali 2, 4, 6, dan 8 jam pada fraksi volume 40\%, 50\%, 60\%, 70\% dengan variasi ketebalan ketebalan $5 \mathrm{~mm}, 10 \mathrm{~mm}, 15 \mathrm{~mm}, 20 \mathrm{~mm}$ pada pengujian bending paling optimal yaitu spesimen tebal $5 \mathrm{~mm}$ pada Vf 50\% sebesar 2,08 Mpa dan pada uji impak paling optimal komposit serat sekam padi acak yaitu spesimen dengan tebal $5 \mathrm{~mm}$ Vf $50 \%$ yaitu sebesar 0,0906 J/mm ${ }^{2}$, selanjutnya engamatan struktur makro didapatkan jenis patahan broken fiber.
\end{abstract}

Kata Kunci: sekam padi, urea formadehyde, bending, impak

\section{PENDAHULUAN}

Sebagai negara yang bahan utama sebagai makanan adalah padi maka Indonesia merupakan negara yang berpenghasilan padi dimana Saat ini pemanfaatan sekam padi tersebut masih sangat sedikit, sehingga sekam tetap menjadi bahan limbah yang mengganggu lingkungan. Salah satu hal yang paling sering dilakukan petani terhadap sekam padi adalah dengan pembakaran., akan tetapi aktivitas ini dapat meningkatkan jumlah polutan dalam udara dan dapat mengganggu kesehatan masyarakat sebenarnya masih banyak cara lebih produktif dan ekonomis dalam pengolahan limbah tersebut.

Resin Urea Formaldehide (UF) merupakan bahan pendukung resin Fenol Formaldehide yang penting karena dapat memberikan warna terang. Selain itu, laju pengerasan pada temperatur kamar yang cepat membuat resin ini cocok digunakan sebagai perekat produk core karena komponen core di dalam struktur panel komposit sandwich menderita pembebanan yang rendah.

Jurnal Kajian Teknik Mesin

Vol. 1 No. 2 
Batasan masalah dalam penelitian ini ditujukan untuk membahas harga kekuatan bending dan impak pada fraksi volume $40 \%, 50 \%, 60 \%, 70 \%$ dan ketebalan $5 \mathrm{~mm}, 10 \mathrm{~mm}, 15 \mathrm{~mm}, 20$ $\mathrm{mm}$ dari komposit berpenguat sekam padi dan bermatrik urea formaldehide dengan proses press mold.

Maksud dari penelitian ini untuk mengetahui kekuatan bending dan kekuatan impak serta struktur patahan pada pengujian bending dan pengujian impak dengan Foto Makro.

Penggunaan sekam padi disamping harganya murah juga mudah didapatkan, ukuran dari serbuk sekam padi yaitu $200 \mu \mathrm{m}, 250 \mu \mathrm{m}, 355 \mu \mathrm{m}, 400 \mu \mathrm{m}$. sedangkan bijih plastik yang digunakan yaitu polietilene jenis HDPE (High Density Polietilen). Sedangkan ukuran fraksi volume serbuk sekam padi dan polietilene adalah 5\%:95\%, 10\%: 90\%, 15\%: 85\%, 20\%:80\%, 25\%:75\%, 30\%:70\%, 35\%:65\%, 40\%:60\%. Metode pengujian komposit ini menggunakan uji impak jenis Charpy. Berdasarkan hasil percobaan dapat disumpulkan bahwa ada pengaruh variabel mesh serbuk sekam padi dengan fraksi volume serbuk sekam padi terhadap kekuatan impak komposit [1].

Kekuatan bending dan tarik komposit berpenguat sekam padi dengan variasi fraksi volume $30 \%, 40 \%, 50 \%$, 60\%, dan 70\%, bermatrik polyester. Fraksi volume serat 30\% diperoleh kekuatan bending rata-rata sebesar 16,16 Mpa, fraksi volume serat 40\% diperoleh kekuatan bending rata-rata sebesar 20,42 Mpa, fraksi volume serat 50\% diperoleh kekuatan bending rata-rata sebesar 19,39 Mpa, fraksi volume serat 60\% diperoleh kekuatan bending rata-rata sebesar 17,08 Mpa, fraksi volume serat $70 \%$ diperoleh kekuatan bending rata-rata sebesar 20,76 Mpa. Sedangkan untuk pengujian tarik fraksi volume $30 \%$ diperoleh kekuatan tarik rata-rata sebesar 15,12 Mpa, fraksi volume 40\% diperoleh kekuatan tarik sebesar 16,31 Mpa, fraksi volume 50\% diperoleh kekuatan tarik rata-rata sebesar 16,01 Mpa, fraksi volume 60\% diperoleh kekuatan tarik sebesar 14,82 Mpa, fraksi volume $70 \%$ diperoleh kekuatan tarik ratarata sebesar 16,23 Mpa [2].

\section{DASAR TEORI}

Komposit adalah suatu bahan yang merupakan gabungan atau campuran dari dua material atau lebih pada skala makroskopis untuk membentuk material ketiga yang lebih bermanfaat. Material komposit merupakan bahan yang homogen yang dibuat dengan cara penggabungan fisis antara dua atau lebih jenis material untuk memperoleh karakteristik dan sifat tertentu yang diinginkan. Secara garis besar komposit diklasifikasikan menjadi tiga macam, yaitu [3]:

1. Komposit serat (Fibrous Composites)

2. Komposit partikel (Particulate Composites)

3. Komposit lapis (Laminates Composites)

Jurnal Kajian Teknik Mesin

Vol. 1 No. 2 
Penguat (reinforment) serat atau fiber dalam bahan komposit berperan sebagai bagian utama yang menahan beban, sehingga besar kecilnya kekuatan bahan komposit sangat tergantung dari kekuatan serat pembentuknya. Salah satu bahan komposit yang digunakan adalah sekam padi bermatrik urea formaldehide dengan hardener sebesar $1 \%$. Sekam padi adalah bagian terluar penggilingan padi dilakukan.

Matrik berfungsi sebagai pengikat bahan penguat dan sebagai pelindung partikel dari kerusakan oleh faktor lingkungan. Matriks Urea Formaldehide banyak digunakan terutama untuk aplikasi konstruksi ringan, selain itu harganya yang relatif sangat murah. Keuntungan lain matriks Urea Formaldehide adalah mudah dikombinasikan dengan serat, tetapi memiliki kelemahan mudah rapuh terhadap air. Pemberian bahan tambahan hardener jenis $H U-12$ pada resin $U F$ berfungsi untuk mempercepat proses pengerasan cairan resin (curing) pada suhu yang lebih tinggi [4].

Analisis perhitungan pada komposit yaitu:

Pengujian Bending adalah metode test ini digunakan untuk menentukan kekuatan bending dari material terhadap momen lengkung [5].

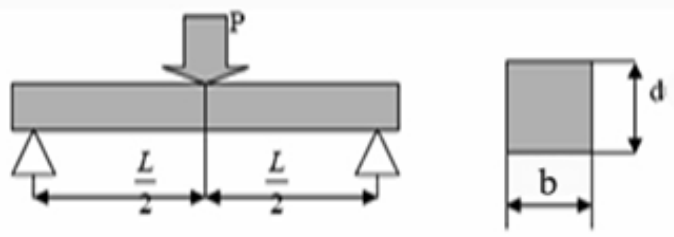

Gambar 1.Penampang uji bending

Momen yang terjadi pada komposit dapat dihitung dengan persamaan:

$M=\frac{P}{2} \times \frac{L}{2}$

Menentukan kekuatan bending menggunakan persamaan:

$\sigma b=\frac{3 \cdot P \cdot L}{2 \cdot b \cdot d^{2}}$

Sedangkan untuk menentukan modulus elastisitas bending menggunakan rumus sebagai berikut:

$\mathrm{E} b=\frac{L^{3} \cdot m}{4 b \cdot d^{3}}$

dimana:

$\mathrm{M}=\operatorname{Momen}(\mathrm{Nmm})$

$\mathrm{L}=$ Panjang span (mm)

$\mathrm{P}=$ Gaya $(\mathrm{N})$

Jurnal Kajian Teknik Mesin

Vol. 1 No. 2 


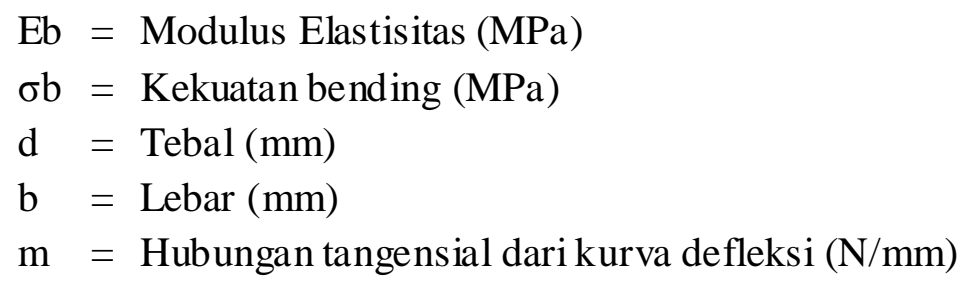

Pengujian impak adalah kekuatan material terhadap beban kejut dapat diketahui dengan cara malakukan uji impak. Semakin kuat ikatan antar molekulnya maka semakin tinggi pula harga impaknya. Pengujian komposit dapat dilakukan dari arah depan dan samping [6].
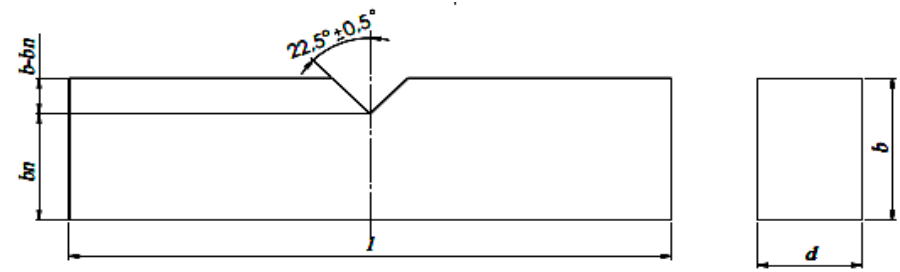

Gambar 2. penampang uji impak

Harga impak benda uji dapat dihitung dengan persamaan berikut:

$E_{\text {serap }}=G \times R(\operatorname{Cos} \beta-\operatorname{Cos} \alpha)$

Keterangan:

$E_{\text {serap }}=$ Energi yang terserap $(\mathrm{J})$

$G \quad=$ Berat beban/pembentur $(\mathrm{N})$

$R \quad=$ Jari-jari putar ke titik berat pembentur $(\mathrm{m})$

$\beta=$ Sudut ayunan pendulum setelah mematahkan spesimen

$\alpha \quad=$ Sudut pendulum sebelum diayunkan

$H I=\frac{E_{\text {serap }}}{A}$

Keterangan:

$H I=$ Harga impak $\left(\mathrm{J} / \mathrm{mm}^{2}\right)$

$E_{\text {serap }}=$ Energi yang terserap $(\mathrm{J})$

$A \quad=$ Luas dibawah takik $\left(\mathrm{mm}^{2}\right)$

\section{METODE DAN TEKNIK PENGUKURAN}

Bahan yang digunakan dalam penelitian ini adalah:

1. Sekam Padi

2. Resin Urea Formaldehide dan katalis HU-12

Alat yang digunakan :

1. Alat Uji Kadar Air

Jurnal Kajian Teknik Mesin

Vol. 1 No. 2 
Alat ini digunakan untuk mengukur kandungan air pada sekam padi.

\section{Timbangan digital}

Digunakan untuk menimbang sekam padi dan urea formaldehide.

3. Cetakan benda uji

Cetakan yang digunakan terbuat dari kaca bening dengan ketebalan $5 \mathrm{~mm}, 10 \mathrm{~mm}, 15 \mathrm{~mm}$, dan $20 \mathrm{~mm}$.

\section{Alat Pressmold}

Alat Pressmold ini digunakan untuk membantu proses pengepresan pada spesimen benda uji komposit.

5. Alat-alat bantu lain

Alat Bantu lain yang digunakan, meliputi : sendok, cutter, kit mobil, pisau, spidol, gergaji besi, obeng, dan gelas ukur.

6. Alat-alat uji bending dan impak

\section{Spesimen}

Pada proses pembuatan spesimen uji. Spesimen yang akan diuji jumlahnya yaitu 3 spesimen tiap variasi volume dan tebal. Untuk uji bending ukuran spesimennya yaitu panjang $96 \mathrm{~mm}$, lebar $12 \mathrm{~mm}$ dan tinggi variasi yaitu 5, 10, 15, 20mm. Untuk uji impak ukuran spesimennya yaitu lebar $19 \mathrm{~mm}$, tebal 5, 10, 15, $20 \mathrm{~mm}$ dan panjang spesimennya sama $165 \mathrm{~mm}$. Dimensi specimen yang akan diuji dapat dilihat pada gambar 3 dan 4 berikut ini:

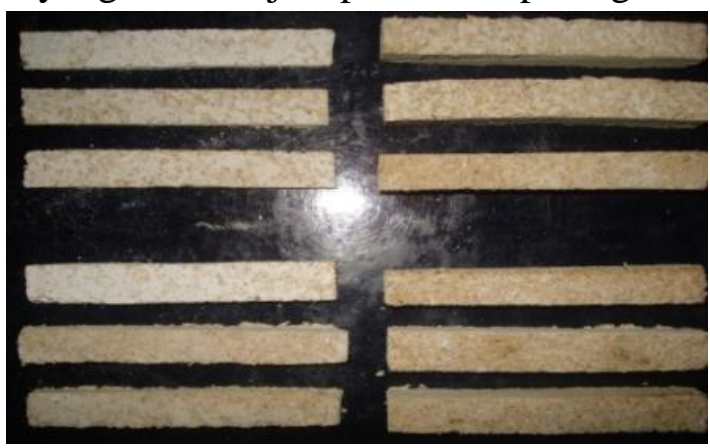

Gambar 3. Spesimen uji bending ko mposit sekam padi bermatrik urea formaldehide.

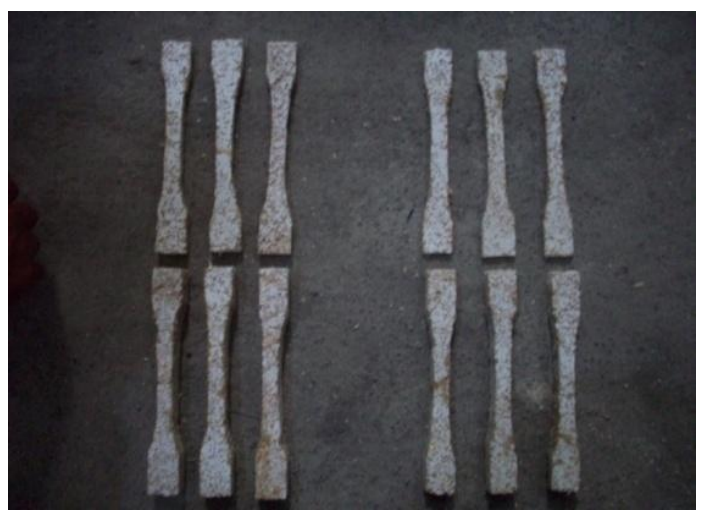

Jurnal Kajian Teknik Mesin

Vol. 1 No. 2 
Gambar 4. Spesimen uji Impak ko mposit sekam padi bermatrik urea formaldehide

Jurnal Kajian Teknik Mesin

Vol. 1 No. 2 


\section{Diagram alir penelitian}

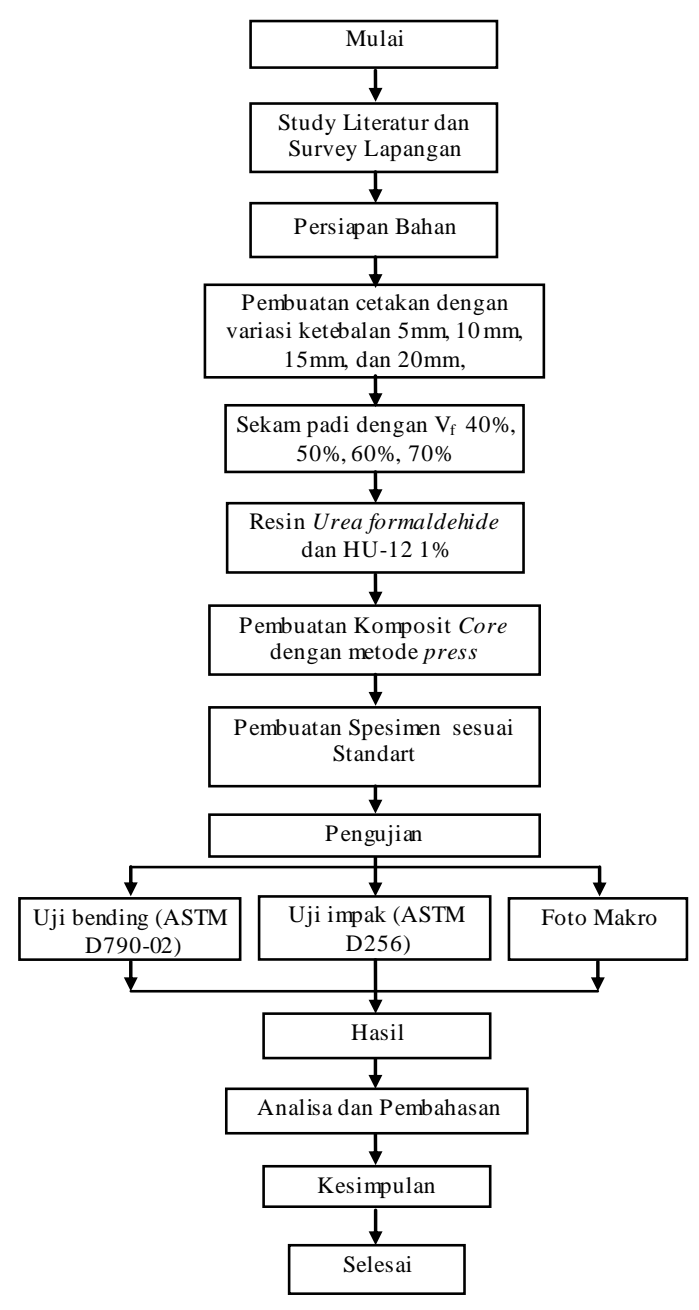

Gambar 5. Diagram alir penelitian

Proses pembuatan komposit sekam padi dengan matrik urea formaldehide adalah sebagai berikut:

1. Pembuatan benda uji.

Pembuatan benda uji menggunakan cetakan dari kaca dengan metode hot press. Bahan yang digunakan yaitu sekam padi dengan matrik urea formaldehide. Dimana perbandingan sekam padi $V_{f}=40 \%, 50 \%, 60 \%, 70 \%$, dan urea formaldehide $V_{m}=70 \%$, $60 \%, 50 \%, 40 \%$, dengan variasi ketebalan 5, 10, 15, $20 \mathrm{~mm}$.

2. Pembuatan spesimen

Proses pemotongan spesimen menggunakan gergaji besi, spesimen dipotong sesuai dengan ukuran standart yang digunakan.

3. Proses pengujian

Pengujian bending dan impak menggunakan alat Universal Testing Machine.

Jurnal Kajian Teknik Mesin

Vol. 1 No. 2 


\section{HASIL DAN PEMBAHASAN}

\section{A. Pengujian Bending}

Tabel 1. Hasil Perhitungan Rata-rata Pengujian tegangan bending

\begin{tabular}{|c|c|c|}
\hline $\begin{array}{c}\text { Tebal } \\
\text { spesimen }\end{array}$ & Fraksi volume & $\begin{array}{c}\text { Tegangan } \\
\text { bending (Mpa) }\end{array}$ \\
\hline \multirow{4}{*}{$5 \mathrm{~mm}$} & $40 \%$ & 1,76 \\
\cline { 2 - 3 } & $50 \%$ & 1,99 \\
\cline { 2 - 3 } & $60 \%$ & 1,73 \\
\hline \multirow{4}{*}{$10 \mathrm{~mm}$} & $70 \%$ & 1,47 \\
\cline { 2 - 3 } & $40 \%$ & 1,60 \\
\cline { 2 - 3 } & $50 \%$ & 1,68 \\
\cline { 2 - 3 } & $60 \%$ & 1,39 \\
\hline \multirow{4}{*}{$15 \mathrm{~mm}$} & $70 \%$ & 1,29 \\
\cline { 2 - 3 } & $40 \%$ & 1,27 \\
\cline { 2 - 3 } & $50 \%$ & 1,49 \\
\cline { 2 - 3 } & $60 \%$ & 1,39 \\
\hline \multirow{5}{*}{$20 \mathrm{~mm}$} & $70 \%$ & 1,09 \\
\cline { 2 - 3 } & $40 \%$ & 0,94 \\
\cline { 2 - 3 } & $50 \%$ & 1,29 \\
\hline
\end{tabular}

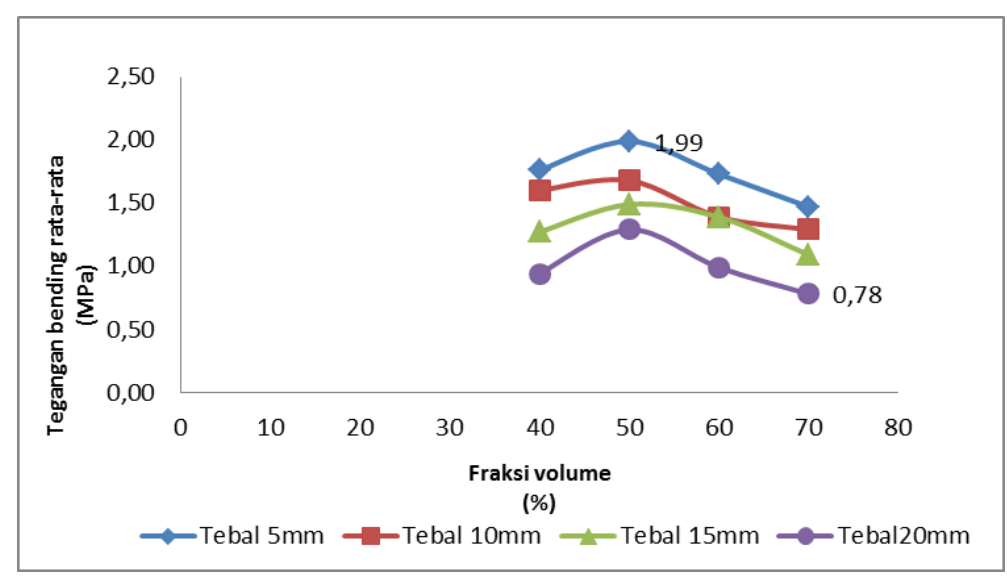

Gambar 6. Grafik Hubungan Tegangan bending rata-rata dengan fraksi volume

Pembahasan uji bending komposit, tegangan bending rata-rata tertinggi pada komposit serat acak sekam padi pada sepesimen tebal $5 \mathrm{~mm}, \mathrm{~V}_{\mathrm{f}} 50 \% \mathrm{sp}$, 50\% uf yaitu $1,99 \mathrm{MPa}$, dan tegangan bending rata-rata terendah pada sepesimen tebal $20 \mathrm{~mm}, \mathrm{~V}_{\mathrm{f}} 70 \% \mathrm{sp}, 30 \%$ uf yaitu $0,78 \mathrm{MPa}$.

\section{B. Pengujian Impak}

Jurnal Kajian Teknik Mesin

Vol. 1 No. 2 
Tabel 2. Hasil Perhitungan Rata-rata Pengujian tegangan impak

\begin{tabular}{|c|c|c|}
\hline $\begin{array}{c}\text { Tebal } \\
\text { spesimen }\end{array}$ & Fraksi volume & $\begin{array}{c}\text { Tegan gan Impak } \\
\left(\mathrm{J} / \mathrm{mm}^{2}\right)\end{array}$ \\
\hline \multirow{4}{*}{$5 \mathrm{~mm}$} & $40 \%$ & 0,0906 \\
\cline { 2 - 3 } & $50 \%$ & 0,0890 \\
\cline { 2 - 3 } & $60 \%$ & 0,0795 \\
\cline { 2 - 3 } & $70 \%$ & 0,0785 \\
\hline \multirow{3}{*}{$10 \mathrm{~mm}$} & $40 \%$ & 0,0587 \\
\cline { 2 - 3 } & $50 \%$ & 0,0572 \\
\cline { 2 - 3 } & $60 \%$ & 0,0480 \\
\cline { 2 - 3 } & $70 \%$ & 0,0454 \\
\hline
\end{tabular}

\begin{tabular}{|c|c|c|}
\hline $\begin{array}{c}\text { Tebal } \\
\text { spesimen }\end{array}$ & Fraksi volume & $\begin{array}{c}\text { Tegan gan Impak } \\
\left(\mathrm{J} / \mathrm{mm}^{2}\right)\end{array}$ \\
\hline \multirow{4}{*}{$15 \mathrm{~mm}$} & $40 \%$ & 0,0463 \\
\cline { 2 - 3 } & $50 \%$ & 0,0471 \\
\cline { 2 - 3 } & $60 \%$ & 0,0450 \\
\cline { 2 - 3 } & $70 \%$ & 0,0464 \\
\hline \multirow{3}{*}{$20 \mathrm{~mm}$} & $40 \%$ & 0,0355 \\
\cline { 2 - 3 } & $50 \%$ & 0,0398 \\
\cline { 2 - 3 } & $60 \%$ & 0,0361 \\
\cline { 2 - 3 } & $70 \%$ & 0,0375 \\
\hline
\end{tabular}

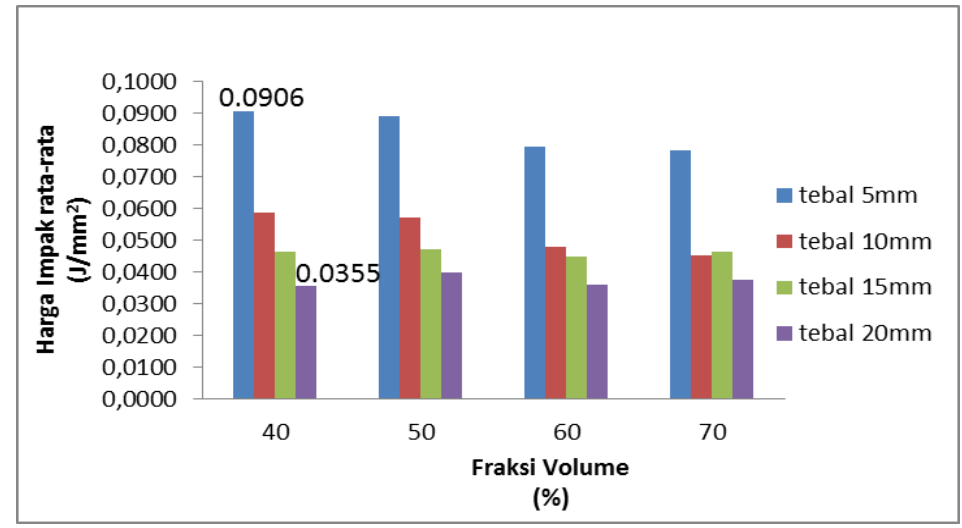

Gambar 7. Grafik Hubungan Kekuatan Impak Rata-rata dengan Fraksi Volume.

\section{Pembahasan uji impak komposit}

Harga impak rata-rata tertinggi pada komposit serat acak sekam padi pada sepesimen tebal 5 $\mathrm{mm}, \mathrm{V}_{\mathrm{f}} 40 \% \mathrm{sp}, 60 \%$ uf yaitu $0,0906 \mathrm{~J} / \mathrm{mm}^{2}$, dan harga impak rata-rata terendah pada sepesimen tebal $20 \mathrm{~mm}, \mathrm{~V}_{\mathrm{f}} 40 \% \mathrm{sp}, 60 \%$ uf yaitu $0,0355 \mathrm{~J} / \mathrm{mm}^{2}$.

\section{Foto Patahan Makro}

\section{Foto Patahan Bending}

Kegagalan akibat gaya tekan (A)

Kegagalan akibat gaya tarik (B)

Jurnal Kajian Teknik Mesin

Vol. 1 No. 2 


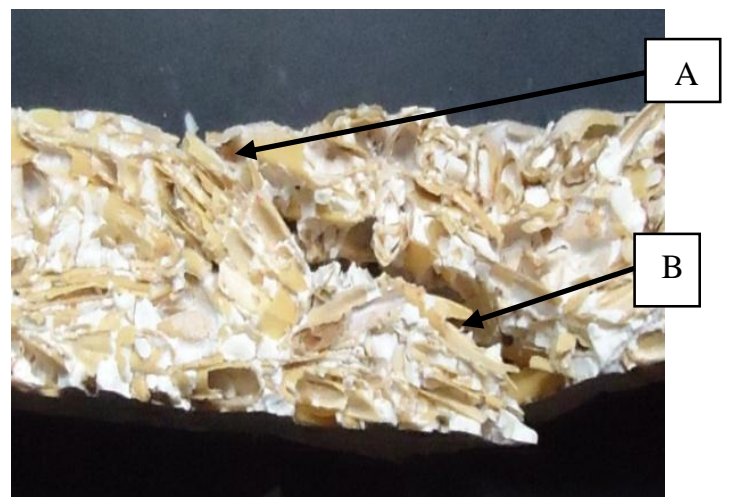

Gambar 8. Foto struktur makro pada spesimen uji bending

2. Foto Patahan Impak

Patah akibat benturan (1)

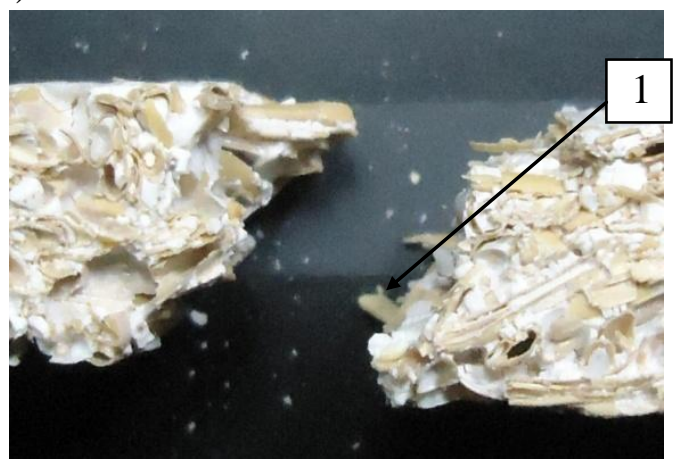

Gambar 9. Foto struktur makro pada spesimen uji Impak.

Pada foto patahan diatas, dapat terlihat kegagalan komposit terjadi pada semua komponennya. Dari hasi foto patahan dapat dilihat bahwa jenis patahan yang terjadi adalah patahan jenis broken fiber. Patahan broken fiber yaitu patahan pada spesimen dimana serat mengalami patah atau rusak dan membentuk seperti serabut.

\section{KESIMPULAN}

Dari data-data yang telah diperoleh menunjukkan harga kekuatan bending yang paling optimal yaitu pada spesimen tebal $5 \mathrm{~mm}$ pada $\mathrm{V}_{\mathrm{f}} 50 \%$ sebesar 2,08 $\mathrm{MPa}$.

Dari data-data yang telah diperoleh harga impak yang paling optimal komposit serat sekam padi acak yaitu pada spesimen dengan tebal $5 \mathrm{~mm} \mathrm{~V}_{\mathrm{f}} 50 \%$ yaitu sebesar $0,0906 \mathrm{~J} / \mathrm{mm}^{2}$.

Pola kegagalan komposit terjadi pada semua komponennya. Dari hasi foto patahan dapat dilihat bahwa jenis patahan yang terjadi adalah patahan jenis broken fiber. Patahan broken 
fiber yaitu patahan pada spesimen dimana serat mengalami patah atau rusak dan membentuk seperti serabut.

\section{DAFTAR PUSTAKA}

[1] Whelly Ardian, 2007. Pengaruh Variabel Mesh Dan Fraksi Volume Serbuk Sekam Padi Terhadap Kekuatan Impak Komposit Polietilen Pada Proses Injection Moulding, Tugas Akhir, Teknik Mesin UMM, Malang.

[2] Akhmad, 2005. Meneliti kekuatan bending dan tarik komposit berpenguat sekam padi dengan variasi fraksi volume 30\%, 40\%, 50\%, 60\%, dan 70\%, bermatrik polyester. Tugas Akhir, Teknik Mesin UMS, Surakarta.

[3] Jones, M. R., 1975, Mechanics of Composite Material, Mc Graw Hill Kogakusha, Ltd.

[4] Smith, F. W., Hashemi, J., 2006, Foundation of Materials Science and Enginering, Mc Graw Hill Companies, Inc.

[5] ASTM D 790-02, 2002, Standard Test Method for Flexural Properties of Unreinforce and Reinforced Plastics and Electrical Insulating Materials, An American National Standard.

[6] ASTM D 638-02, 2002, Standard Test Method for Tensile Properties of Plastics, An American National Standard. 